\title{
Challenges and agroecological approaches in crop production
}

\author{
ZOLTAN BERZSENYI1,2 \\ 1University of Kaposvár, Kaposvár, Hungary \\ ${ }^{2}$ Hungarian Academy of Sciences, Centre for Agricultural Research, Agricultural \\ Institute, Crop Production Department, Martonvásár, Hungary \\ profberzsenyi.zoltan@gmail.com
}

\begin{abstract}
Summary
Never has the need been greater for an ecosystem approach to agriculture. As our global population exceeds 9 billion in the next 30 years, with a concomitant demand for agricultural products, ever more pressure will be placed on our agricultural systems. Meanwhile, climate change is altering the ecological settings in which agriculture is practiced, demanding adaptation. Knowledge generated by long-term research will help to address one of the grand challenges of our time: how to meet sustainably the growing world demand for agricultural products - in a way that minimizes environmental harm and enhances the delivery of a diverse array of ecosystem services.
\end{abstract}

Keywords: long-term experiment, maize, wheat, yield response, indicators of sustainability, stability analysis

\section{Introduction}

The Food and Agriculture Organization of the United Nations (UN) estimates that we will need $60 \%$ more food by 2050 . This is partly due to increasing population. In 2012, the world's population passed the 7 billion mark. The UN predict that the world's population will increase to 9.6 billion by 2050. But a bigger cause of the need for increased population is the changing diets of many consumers, especially those in high-population emerging economics. More plant production is needed to replace fossil fuels and consequently to provide the raw materials for biofuels. However, increasing such uses of plants could consume agricultural resources that could contribute to food production.

It is estimated that $1.16-1.31 \%$ year $^{-1}$ compound rates of increase in grain yield are needed to satisfy projected demand in cereals for food, feed and biofuels for 2050 (Fisher and Edmeades, 2010). The linear rates of cereal yield increase were nearly $3 \%$ of average yield in the 1960s, have fallen to about $1 \%$ of average yield by 2010 . Over the 20 -year period to 2012 the linear rates of yield change for the world have been $33 \mathrm{~kg} \mathrm{ha}^{-1}$ year-1 (wheat), $43 \mathrm{~kg} \mathrm{ha}^{-1}$ year-1 (rice) and $73 \mathrm{~kg} \mathrm{ha}^{-1}$ year- $^{-1}$ (maize). 
Relative rates of yield increase are declining and, expressed relative to predicted yield in 2009 , are $1.1 \%$ year ${ }^{-1}$ for wheat, $1.0 \%$ year $^{-1}$ for rice, and $1.4 \%$ year $^{-1}$ for maize. With the exception of maize in some regions, there is no evidence for exponential growth in yield. Even at a compound rate of $1 \%$, production would increase by only $50 \%$ on the same agricultural area to 2050. Thus there is little doubt that the world needs to continue increasing cereal yields.

\section{Materials and methods}

The long-term experiments were set up by Béla Győrffy in the Agricultural Research Institute of the Hungarian Academy of Sciences in Martonvásár in the late 1950s and early 1960s. The present paper summarizes some results of these experiments based on papers published by the author over the last $10-15$ years.

\section{Crop rotation experiment}

The crop rotation experiment was set up in 1961 in a two-factorial, splitplot design with four replications. The crop sequences formed the main plots and the fertiliser treatments the sub-plots. The seven crop sequences were as follows: 1 . Continuous maize, 2 . Continuous wheat, 3 . Five years maize, three years alfalfa (MA), 4. Five years wheat, three years alfalfa (WA), 5. Two years maize, two years wheat (MW or WM), 6. Three years maize, two years wheat, three years alfalfa (MWA or WAM), 7. Maize, spring barley, peas, wheat (NF). The maize and wheat ratios in the various crop sequences were $25,37.5,60,62.6$ and $100 \%$.

The sub-plots represented five diverse fertilisation systems: A. Unfertilised control, B. $60 \mathrm{t} \mathrm{ha}^{-1}$ farmyard manure (FYM) every 4 years + supplementary NPK, C. $5 \mathrm{t} \mathrm{ha}^{-1}$ straw or $7 \mathrm{t} \mathrm{ha}^{-1}$ maize stalks each year + supplementary NPK, D. NPK mineral fertiliser equivalent to crop uptake, E. Crop uptake of NPK for a yield of $15 \mathrm{t} \mathrm{ha}^{-1}$ maize or $10.5 \mathrm{t} \mathrm{ha}^{-1}$ wheat.

\section{Poly-factorial long-term experiment}

In a long-term experiment with four replications, established on medium heavy loam soil in 1960, the effect of five crop production factors (tillage, fertilisation, plant density, variety, weed control) was studied in seven treatment combinations. Each of the factors was tested at two levels: minimum and optimum. In Treatment 1 all the factors were minimum and in Treatment 2 all the factors were optimum. In Treatments 3-7 one of the factors was minimum, while all the others were optimum. The minimum factors in the various treatments were tillage in Treatment 3 , fertilisation in Treatment 4, plant density in Treatment 5, variety in Treatment 6 and weed control in Treatment 7 . 
Long-term $N$-fertilization experiments

The $\mathrm{N}$ fertiliser responses of maize hybrids were investigated in two diverse environments: a 50-year-old monoculture (stress environment) and a Norfolk crop rotation (optimum environment). In both experiments various $\mathrm{N}$ doses were applied with identical supplies of $\mathrm{P}$ and $\mathrm{K}$. In the maize monoculture the $\mathrm{N}$ fertiliser doses were the following (in $\mathrm{kg} \mathrm{ha}^{-1}$ ): $0,80,160$ and 240 (designated as $\mathrm{N}_{0}, \mathrm{~N}_{80}, \mathrm{~N}_{160}$ and $\mathrm{N}_{240}$ ), while in all the treatments the $\mathrm{P}$ and $\mathrm{K}$ doses were $160 \mathrm{~kg} \mathrm{ha}^{-1}$. In the crop rotation (maize, spring barley, peas, winter wheat) the $\mathrm{N}$ fertiliser responses of the maize hybrids were examined over a range of $0-280 \mathrm{~kg} \mathrm{~N} \mathrm{ha}^{-1}$ in 40 $\mathrm{kg} \mathrm{ha}^{-1}$ steps. The $\mathrm{P}$ and $\mathrm{K}$ quantities were the same in all cases $(120 \mathrm{~kg}$ $\mathrm{ha}^{-1}$ ). The effect of the year on the $\mathrm{N}$ fertiliser response was investigated in the maize monoculture between 1970 and 2009, together with the $\mathrm{N}$ fertiliser×maize hybrid interaction. In the years 1995-2007 the $\mathrm{N}$ fertiliser responses of the hybrids were compared at four $\mathrm{N}$ fertiliser levels $\left(\mathrm{N}_{0}\right.$, $\mathrm{N}_{80}, \mathrm{~N}_{160}$ and $\mathrm{N}_{240}$ ) in monoculture and crop rotation, using five hybrids from different maturity groups in both experiments.

Long-term fertilization experiment

In a long-term field experiment (established in 1961) four $\mathrm{N}$ treatments were applied at $0,100,200$, and $300 \mathrm{~kg} \mathrm{ha}^{-1}$. These $\mathrm{N}$ treatments were combined with different $\mathrm{P}$ and $\mathrm{K}$ rates, $\mathrm{N}_{0}$ with $0 \mathrm{~kg}^{-1} \mathrm{P}$ and $\mathrm{K}, \mathrm{N}_{100}$ with $48 \mathrm{~kg} \mathrm{ha}^{-1} \mathrm{P}$ and $87 \mathrm{~kg} \mathrm{ha}^{-1} \mathrm{~K}, \mathrm{~N}_{200}$ with $96 \mathrm{~kg} \mathrm{ha}^{-1} \mathrm{P}$ and $174 \mathrm{~kg} \mathrm{ha}^{-1}$ $\mathrm{K}$, and $\mathrm{N}_{300}$ with $144 \mathrm{~kg} \mathrm{ha}^{-1} \mathrm{P}$ and $261 \mathrm{~kg} \mathrm{ha}^{-1} \mathrm{~K}$. The plant population density was evaluated at 3, 5, 7, and 9 plants $\mathrm{m}^{-2}$. The hybrids, Mara (FAO 297), Norma (FAO 380), and Gazda and Maraton (FAO 450), were characterized as short-, mid-, and full-season, respectively. The study was arranged as a split-split-split plot design with four blocks. The main plot was fertilization treatment, subplot was density, and sub-subplot was hybrid.

\section{Plant density experiment}

The experiment was set up in a split plot design (main plot: plant density, subplot: hybrid) in four replication. There were six plant densities (1000 plants ha-1): 20, 40, 60, 80, 100 and 120, while the subplots consisted of three maize hybrids with different vegetation periods (FAO numbers): Mara 290, Mv 355: 390, Florencia: 530. Samples for the destructive plant analysis were taken every two weeks from 17-28 days after sowing until physiological maturity. The separated plant parts were dried at $105{ }^{\circ} \mathrm{C}$ in a drying cabinet for $48-96 \mathrm{~h}$ for the determining of dry mass. The Richards function (Hunt, 1982) was fitted to the dry matter of the whole plant and grain yield. 


\section{Analysis of variance}

Analysis of variance (ANOVA) for the relevant experimental design was first applied to determine the effect of the treatments on the yield in each year. In the second step, combined two-factor ANOVA was used to evaluate the main effects and interactions of the treatments, taking the years into account.

\section{Stability analysis}

The stability of the treatments was examined using stability analysis for single variables (variance and regression parameters) and multiple variables (AMMI model). The AMMI (Additive Main effect and Multiplicative Interaction) model is a combination of ANOVA and principal component analysis (PCA). In the first part of the AMMI analysis, ANOVA is carried out to divide the total variation into three orthogonal sources: genotype $(\mathrm{G})$, environment $(\mathrm{E})$ and the genotype $\times$ environment interaction $(G \times E)$. In the second step PCA is applied to dissect the $G \times E$ interaction into several orthogonal PCA variables (axes).

\section{Results and discussion}

\section{Inputs and efficient use of resources}

All new or improved input (varieties, chemicals, husbandry, fertilizers) to the crop production have played a vital part in the increases in yield achieved over the last seventy years. But it is difficult in modern production systems to identify their individual contributions. The reason is that inputs interact. In highly developed agricultural systems the large increases in yields have come from interactions between inputs (Cooke, 1982). Farmers need to test all new advances that may increase the yields of their crops and they must fit them in with other practices to form a package of inputs.

Fertilizers are the predominant input into crop production and account for almost half of the energy used in world agriculture. Without $\mathrm{N}$ fertilizer, wheat yields would be about $2 \mathrm{t} \mathrm{ha}^{-1}$, similar to those in the unfertilized control plots in the Györffy classical long-term experiments at Martonvásár. However, the rise in fertilizer $\mathrm{N}$ applications over years has been accompanied by varietal improvement and other inputs have been introduced, multiplying the opportunities for synergistic interactions.

The effect of $\mathrm{N}$ fertilisation and the year on maize grain yields is presented on the basis of data for 14 dry and 26 wet years between 1970 and 2009 (Figure 1). It is clear from the figure that the maize yield was smallest in the $\mathrm{N}_{0}$ treatment in both types of years, significantly increasing in the $\mathrm{N}_{80}$ and $\mathrm{N}_{160}$ treatments. The highest yields were 
obtained at the $160 \mathrm{~kg} \mathrm{ha}^{-1} \mathrm{~N}$ rate. When the dry and wet years were compared, the yield surplus $\left(\mathrm{t} \mathrm{ha}^{-1}\right)$ achieved at each $\mathrm{N}$ rate in the wet years amounted to: $\mathrm{N}_{0}: 1.567, \mathrm{~N}_{80}: 2.616, \mathrm{~N}_{160}: 2.764, \mathrm{~N}_{240}: 2.740$.

Figure 2 illustrates the $\mathrm{N}$ fertilizer responses of maize hybrids in a 40year monoculture and in a Norfolk crop rotation in the years 1995-2007.

The maize yield was higher at all $\mathrm{N}$ fertilizer levels in the crop rotation (mean yield surplus $3.98 \mathrm{t} \mathrm{ha}^{-1}$ ) than in the monoculture, but the difference was greatest in the treatment without $\mathrm{N}$ fertilization (5.70 tha1). In these experiments the optimum rate of $\mathrm{N}$ fertilization proved to be $120-180 \mathrm{~kg} \mathrm{ha}^{-1}$ in a monoculture and $60-120 \mathrm{~kg} \mathrm{ha}^{-1}$ in the crop rotation.

Figure 1. Effect of $N$ fertilisation on the grain yield of maize in dry (14 years) and wet years (26 years) between 1970 and 2009

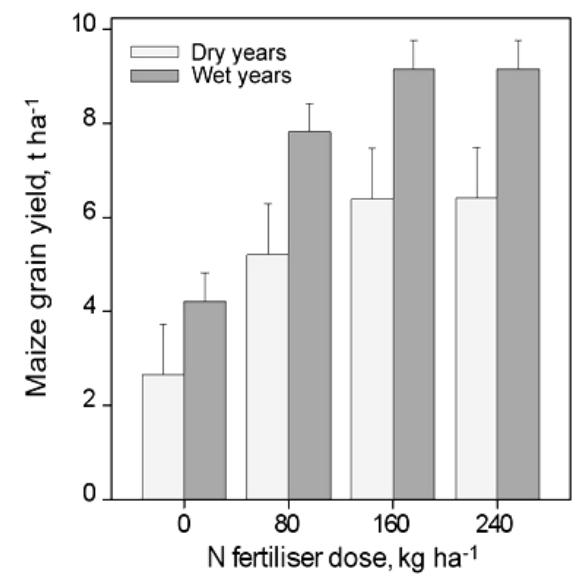

Figure 2. $N$ fertiliser responses of maize hybrids in monoculture and crop rotation (1995-2007)

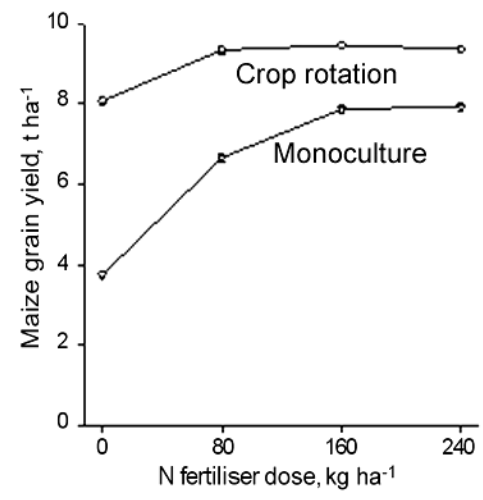


One interaction that has received a lot of attention is that between $\mathrm{N}$ application rate and grain yield as influenced by variety. The effect of the $N$ fertiliser $\times$ maize hybrid interaction on the yield was evaluated by means of combined analysis of variance in a maize monoculture between 1985 and 1994 (on the same five hybrids) and between 1995 and 2002 (on the same seven hybrids), taking the years into account (Berzsenyi, 2010).

The significant interaction between $\mathrm{N}$ fertiliser and the maize hybrid indicated that the differences between the hybrids were not the same at different $\mathrm{N}$ fertiliser levels. Further dissection of the $\mathrm{N}$ fertiliser $\times$ hybrid interaction SS using the orthogonal polynomials method revealed that the $\mathrm{N}$ fertiliser $\times$ hybrid interaction could be attributed primarily to differences in the linear section of the yield responses of the hybrids to $\mathrm{N}$ fertiliser. However, there may also be significant differences in the second or third degree components (Figure 3). In nearly all cases there is a strong interaction between variety and application level such that the response to $\mathrm{N}$ fertilizers is enhanced in more recent varieties.

Figure 3. N fertiliser $\times$ maize hybrid interaction during the periods 1985-1994 and 1995-2002 based on measured yield data
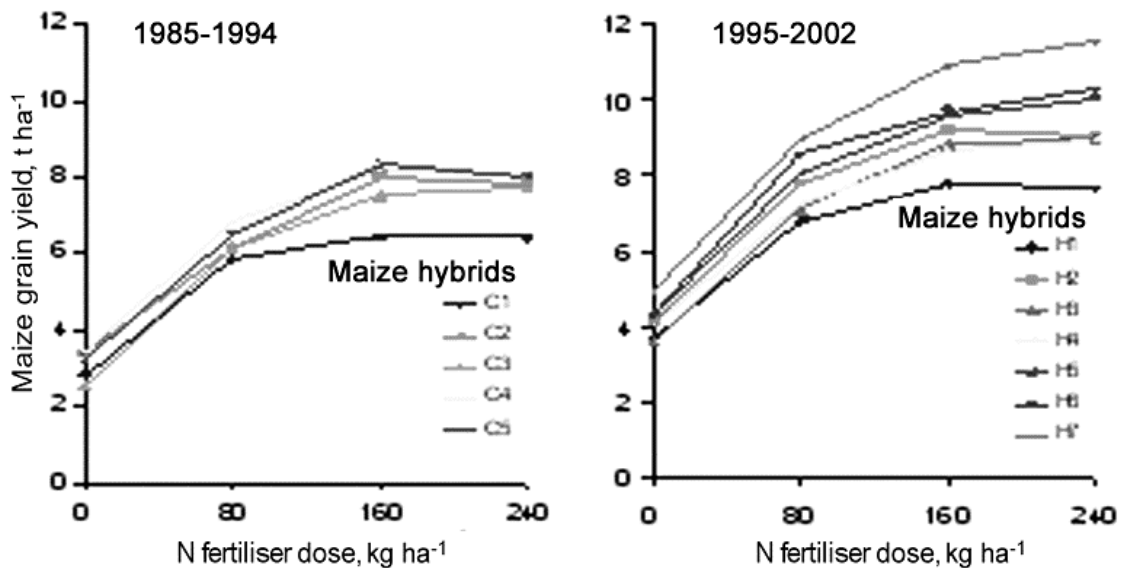

Note: vegetation periods increase from $\mathrm{C}_{1}$ and $\mathrm{H}_{1}$ to $\mathrm{C}_{5}$ and $\mathrm{H}_{5}$.

Figure 4 demonstrates the response of hybrids to density changes with the application of $200 \mathrm{~kg} \mathrm{~N} \mathrm{ha-1.} \mathrm{Based} \mathrm{on} \mathrm{quadratic} \mathrm{equations,} \mathrm{the}$ optimum density was at 7.48, 8.11, 9.22, and 7.53 plants $\mathrm{m}^{-2}$ for Mara, Norma, Gazda, and Maraton, respectively. The respective maximum crop yield was at $6.09,7.28,7.13$, and $7.30 \mathrm{t} \mathrm{ha}^{-1}$. Results show that these four hybrids cannot be comparatively evaluated for crop-yield potential under a single plant population density due to a strong hybrid $\times$ density interaction. Even though Norma and Gazda have equal crop-yield 
potential with Maraton, the latter accomplishes maximum grain yield at considerably lower plant population density. Furthermore, these results indicate that Maraton hybrid is able to attain high yield potential at relatively wide range of densities at 6 to 9 plants $\mathrm{m}^{-2}$, whereas Norma and Gazda reach it at 8.11 , and 9.22 plants $\mathrm{m}^{2}$, respectively. This indicates that Maraton is a comparatively less density-dependent hybrid.

Figure 4. Grain yield response of four hybrids to density changes at the $200 \mathrm{~kg} \mathrm{ha}^{-1} \mathrm{~N}$ treatment and over $10 \mathrm{yr}$ - the quadratic equations and the respective optimum densities and potential (maximum) yields are also shown

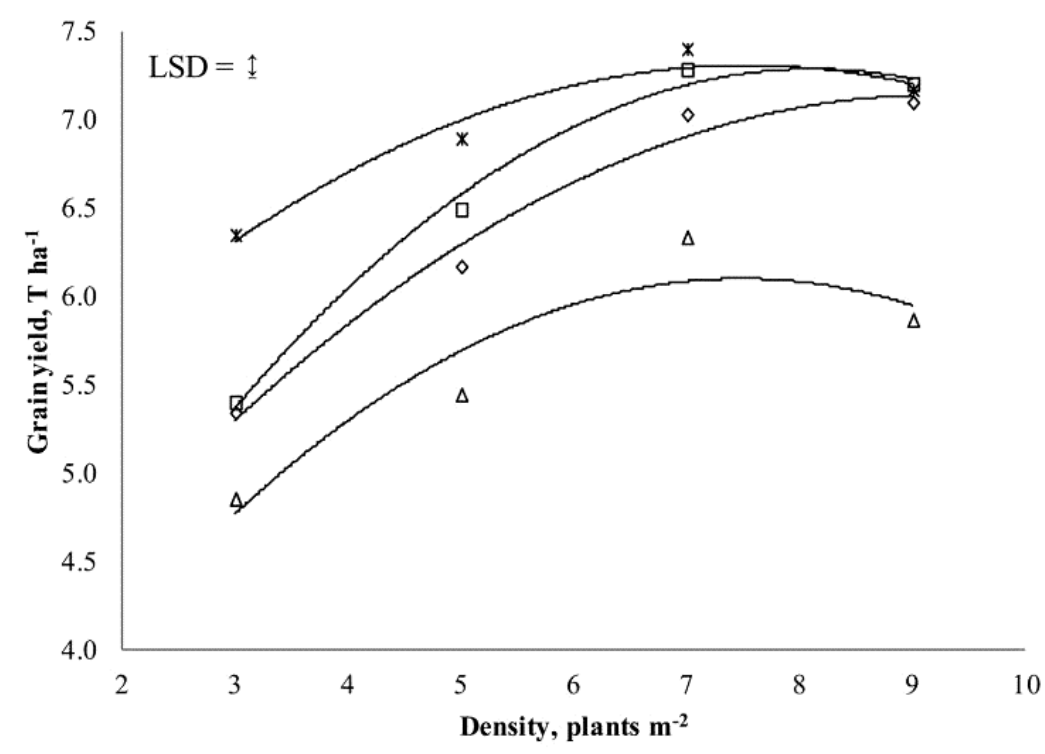

$\triangle$ Mara $\square$ Norma $\diamond$ Gazda $\times$ Maraton

\begin{tabular}{llcc}
\hline \multicolumn{1}{c}{ Hybrid } & \multicolumn{1}{c}{ Quadratic equation } & $\begin{array}{c}\text { Optimum density } \\
\left(\text { plants } \mathrm{m}^{-2}\right)\end{array}$ & $\begin{array}{c}\text { Potential } \\
\text { yield }\left(\mathrm{T} \mathrm{ha}^{-1}\right)\end{array}$ \\
\hline Mara & $\mathrm{y}=-0.0661 \mathrm{x}^{2}+0.989 \mathrm{x}+2.3954\left(\mathrm{R}^{2}=0.88\right)$ & 7.48 & 6.09 \\
Norma & $\mathrm{y}=-0.0733 \mathrm{x}^{2}+1.189 \mathrm{x}+2.4593\left(\mathrm{R}^{2}=0.99\right)$ & 8.11 & 7.28 \\
Gazda & $\mathrm{y}=-0.0475 \mathrm{x}^{2}+0.8758 \mathrm{x}+3.0957\left(\mathrm{R}^{2}=0.98\right)$ & 9.22 & 7.13 \\
Maraton & $\mathrm{y}=-0.0485 \mathrm{x}^{2}+0.7305 \mathrm{x}+4.5529\left(\mathrm{R}^{2}=0.96\right)$ & 7.53 & 7.30 \\
\hline
\end{tabular}

Comparing hybrids within the same maturity group, Maraton hybrid had lower optimum density than Gazda, by almost 1.7 plants $\mathrm{m}^{-2}$ (Berzsenyi and Tokatlidis, 2012).

Density and hybrid selection (short vs. long season) for dryland production depend on available seasonal water. It is difficult to indicate optimum density for density-dependent hybrids. The risk of potential yield loss for density-dependent Norma hybrid can be reduced by using 
optimum densities for favorable seasons. An efficient way may be to focus on density-independent hybrids. This is supported by a relative performance of later-maturing Maraton hybrid compared with the earlier maturing Mara and Norma hybrids. Choosing hybrids that combine density independence with a relatively short time to reach maturity may be ideal solution for regions with insufficient rainfall in late season.

Farmers growing density-independent hybrids may apply low plant population, recommended for dry season, without much risk of yield potential loss in the season with above average rainfall.

For a number of crops, about half of the increases in yield is attributable to plant breeding and half to improved agronomy and management. Moreover, the improvement in yield potential by breeding has hinged, to a large extent, on the provision of better agronomic support for the crop.

A succession of new inputs has been essential for the continuing rise in crop yields, but perhaps even more important than the succession of inputs in agriculture is their synergism and the opportunities they create for further positive interactions. The continuing growth in the number and scope of these positive interactions through plant breeding and agronomic innovations helps to keep diminishing returns at bay (Evans, 1991).

The effect of the crop production factors in increasing maize yields is depicted in Figure 5, averaged over the 42 years. The greatest difference in the mean yield response was found between treatments where all the factors were unfavourable $\left(2.09 \mathrm{t} \mathrm{ha}^{-1}\right)$ or favourable $\left(8.59 \mathrm{t} \mathrm{ha}^{-1}\right)$. When only one factor was unfavourable and all the others favourable, the depth of soil tillage was found to have the least effect on maize yields (mean yield response: $8.32 \mathrm{t} \mathrm{ha}^{-1}$ ), while both fertilisation and genotype had a substantial influence on the yield (mean yield response: 5.21 and $4.98 \mathrm{t}$ $\mathrm{ha}^{-1}$, respectively). The unfavourable level of plant density or weed control led to yield reductions of 2.2 and $1.6 \mathrm{t} \mathrm{ha}^{-1}$ (mean yield responses of 6.36 and $7.01 \mathrm{t} \mathrm{ha}^{-1}$ ). Based on this 42-year data series, the crop production factors were found to make the following contributions to yield increases in maize: variety $32.6 \%$, fertilisation $30.6 \%$, plant density 20.2\%, weed control $14.2 \%$ and soil tillage 2.4\% (Berzsenyi and Dang, 2008).

The main effects of year and treatments and the interactions were also examined using AMMI analysis, which combines ANOVA and principal component analysis (Berzsenyi and Dang, 2008). The first and second principal components (PCA1, PCA2) explained $71.4 \%$ of the interaction SS. The results of the AMMI analysis are illustrated in Figure 6, with the yield average on the $X$ axis and the value of the first principal component on the $\mathrm{Y}$ axis, for seven treatments in 42 environments (years). The higher 
the value of the principal component, the greater the contribution of the treatment to the interaction, i.e. the lower the yield stability. It can be seen that Treatments 7,6,1 and 4 made the greatest contributions to the interaction, while Treatments 2,3 and 5 had the greatest yield stability.

Figure 5. Effect of crop production factors on maize grain yield increments in a long-term experiment (Martonvásár 1960-2001)

\begin{tabular}{|c|c|c|c|c|}
\hline $\mathrm{T}$ & $\mathrm{F}$ & $\mathrm{D}$ & $\mathrm{V}$ & $\mathrm{W}$ \\
\hline 0 & 0 & 0 & 0 & 0 \\
\hline 1 & 1 & 1 & 0 & 1 \\
\hline 1 & 0 & 1 & 1 & 1 \\
\hline 1 & 1 & 0 & 1 & 1 \\
\hline 1 & 1 & 1 & 1 & 0 \\
\hline 0 & 1 & 1 & 1 & 1 \\
\hline 1 & 1 & 1 & 1 & 1 \\
\hline
\end{tabular}

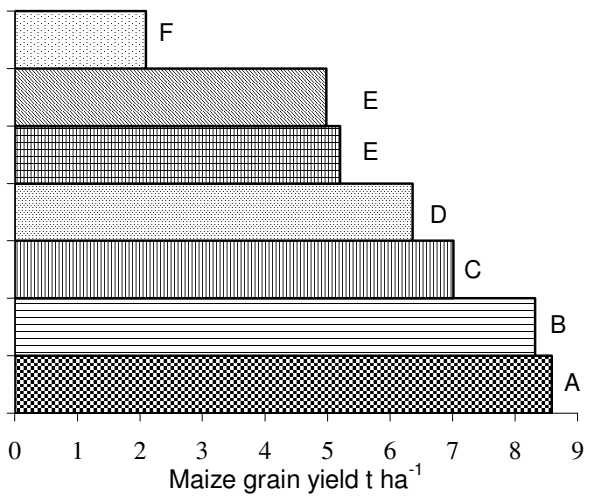

Note: treatments - T: Depth of soil tillage, F: Fertilisation, D: Plant density, V: Variety, W: Weed control. Each factor at two levels: 0: Minimum level, 1: Optimum level. Treatments designated with the same letter did not differ significantly according to Duncan's test.

Figure 6. Plot of the mean yields and first principal component scores of crop production factors in 42 environments

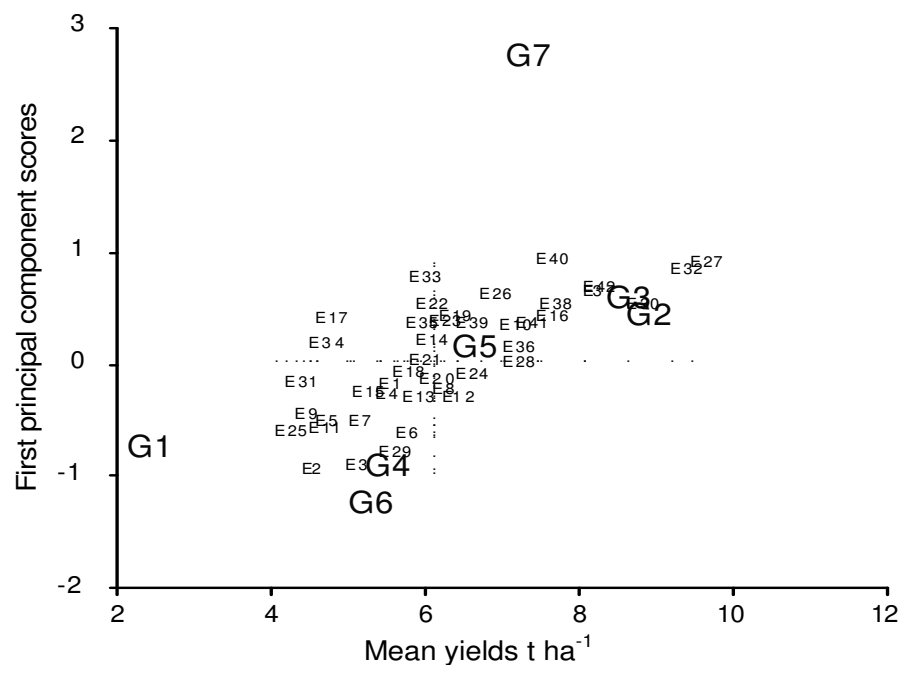

G1-G7: the experimental treatments, E1-E42: the environments (years) 
Evaluating the mean performance and yield stability together, the best treatment was Treatment 2, which contained the favourable combination of all production factors, followed by Treatment 3, where tillage was at the unfavourable level and the other factors were favourable.

\section{Plant growth analysis}

Plants may differ widely in the rate of production of their total dry weight or of their harvestable dry weight. Some of these differences in production of total or harvestable dry weight are related to environmental conditions. Others are associated with inherent differences. Identifying the physiological, biochemical or morphological characteristics which are responsible for inherent or environmentally induced variation in plant growth or yield, requires a careful growth analysis. Plant growth analysis is an explanatory, holistic and integrative approach to interpreting plant form and function (Hunt, 1982). It is to be expected that an analysis of plant production and its underlying processes will lead to further understanding of crop yield and of the functioning of species in their environment.

Plant density had a significant effect on the dynamics of dry matter accumulation, absolute growth rate (AGR) and absolute acceleration rate (AAR). There was a significant reduction in the asymptotic maximum (A) of grain yield as the plant density increased, but the magnitude of the reduction varied with the hybrid (Figure 7). The following values (g plant $\left.{ }^{1}\right)$ were recorded at each plant density $\left(10^{3}\right.$ plants ha-1), averaged over the hybrids: 20: 280.0, 40: 215.3, 60: 169.4, 80: 147.8, 100: 116.7, 120: 103.6.

There was no significant difference between the grain yield maximums recorded at plant densities of 100 and 120 thousand plants ha- ${ }^{-1}$ (Berzsenyi and Dang, 2007).

In long-term experiments, growth analysis is an ideal method for comparing the growth of plants and the agronomic and ecological factors influencing growth. Growth analysis can be used for the long-term analysis of photosynthetic production, bridging the gap between the description of plant biomass production and analysis involving physiological methods. The growth parameters describe the growth of whole plants or individual organs, and the relationship between assimilating organs and dry matter production, thus facilitating the multifactorial evaluation of the long-term effect of experimental treatments. 
Figure 7. Effect of the plant density on the dynamics of dry matter accumulation, absolute growth rate and absolute acceleration rate of the grain yield of the maize hybrid Mv 355 in 1999, as determined by fitting the Richards function
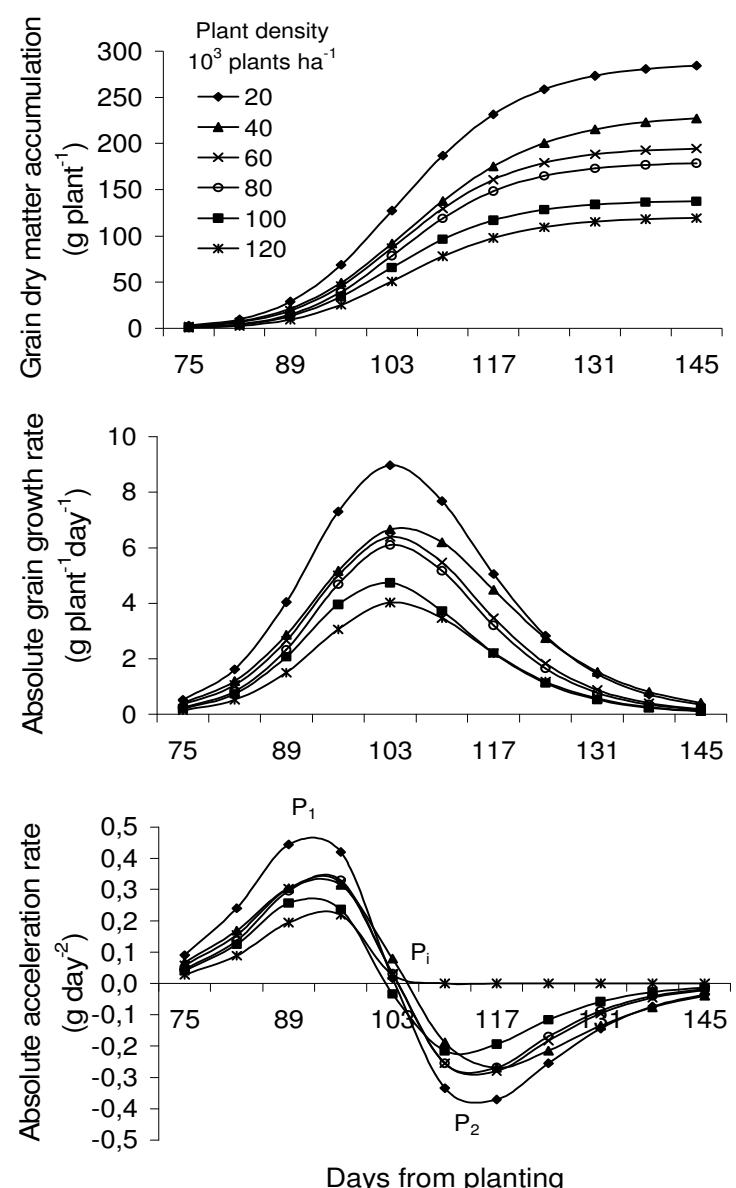

Note: $P_{1}, P_{i}$ and $P_{2}$ show the critical points (AAR $\max$, inflection point, $A A R_{\min }$ ) of growth.

\section{Ecosystem approach to agriculture}

Agricultural ecosystems are managed to produce food, fuel, and fiber but also have the potential, when managed appropriately, to provide society a host of other benefits known as ecosystem services. Examples include climate change mitigation, clean drinking water, providing soil fertility, beneficial insect habitat, and various cultural amenities like outdoor reservation and green space. The delivery of these services depends on how agriculture is managed as fields and landscapes. 
Historically we have managed agricultural systems more for yield than for other ecosystem services, though evidence suggests that many of these other services can be promoted without sacrificing yield. And increasingly, we realize how issues of environmental quality that extend well beyond the farm challenge the sustainability of agriculture in the long term.

A sustainable agriculture maintains the resource base upon which it depends, relies on a minimum of artificial inputs from outside the farm system, manages pests and diseases through internal regulating mechanisms, and is able to recover from the disturbances by cultivation and harvest (Gliessman, 2015). Natural ecosystems and industrial agroecosystems are very different. The latter are generally more productive but far less diverse than the former. And unlike natural systems, industrial agroecosystems are far from self-sustaining. Their productivity can be maintained only with large additional inputs of energy and materials from external, human-produced sources; otherwise they quickly degrade to a much less productive level. The greater the structural and functional similarity of an agroecosystem to the natural ecosystems, the greater the likelihood that the agroecosystem will be sustainable. In a sustainable agroecosystem, the goal is to optimize the process of productivity so as to ensure the highest yield possible without causing environmental degradation. Experimentation allows us to identify the organisms and processes responsible for different outcomes, and suggests ways that different systems might be managed to optimize the delivery of the most valued ecosystem services.

A characteristic of intensive agriculture is its severe reduction of plant diversity. Rotational diversity matters to the delivery of ecosystem services, including yield. Simplified rotations and larger fields lead to simplified landscapes, because total cropland becomes constrained to two or three dominant species. That continuous monocultures suffer a yield penalty that persists even in the presence of modern chemicals is well known. For millennia, agriculturalists have used multispecies rotations to improve yields by advancing soil fertility and suppressing pests and pathogens.

In our experiment, the yields of maize and wheat grown in monoculture were always lower than in crop rotation, but the yield losses in monoculture were greater for wheat than for maize (Figure 8-9). The yield-increasing effect of crop rotation was inversely proportional to the ratio of maize or wheat in the sequence. Averaged over the fertiliser treatments (A-E), the Norfolk rotation (NF) had the greatest yieldincreasing effect ( $0.904 \mathrm{t} \mathrm{ha}^{-1}$ for maize and $1.664 \mathrm{t} \mathrm{ha}^{-1}$ for wheat). This was followed by the maize-wheat-alfalfa (MWA) triculture (0.853 t ha-1 for maize and $1.223 \mathrm{t} \mathrm{ha}^{-1}$ for wheat), the wheat-maize (MW) diculture 
(0.490 $\mathrm{t} \mathrm{ha}^{-1}$ for maize and $0.732 \mathrm{t} \mathrm{ha}^{-1}$ for wheat), the maize-alfalfa (MA) rotation $\left(0.376 \mathrm{t} \mathrm{ha}^{-1}\right)$ and the wheat-alfalfa (WA) sequence $\left(0.471 \mathrm{t} \mathrm{ha}^{-1}\right)$.

Figure 8. Effect of crop rotation and fertilisation on the grain yield of maize compared with a monoculture (1961-2000)
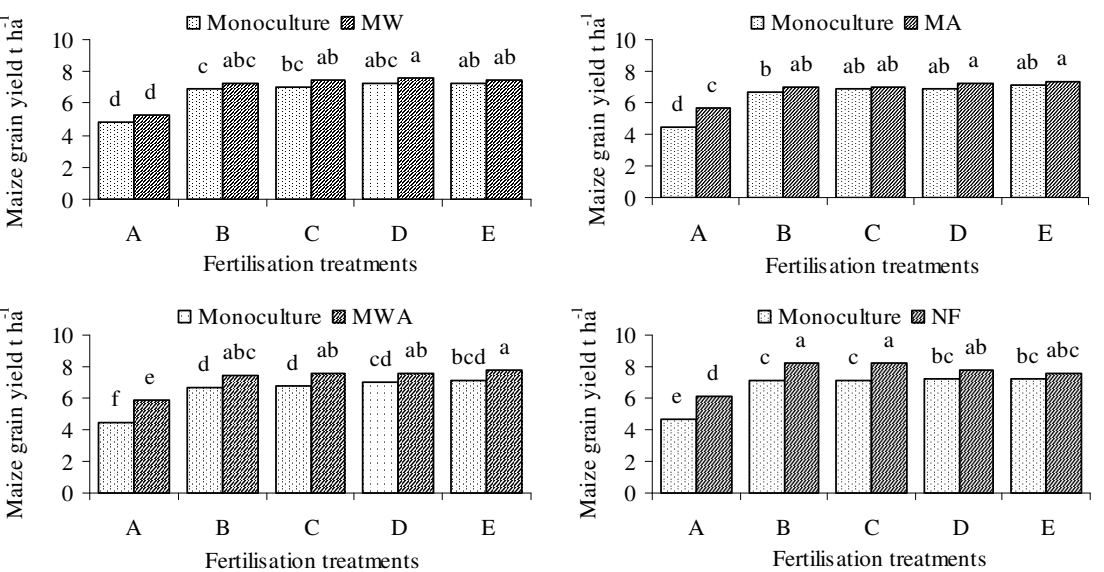

Note: MW: maize-wheat; MA: maize-alfalfa; MWA: maize-wheat-alfalfa; NF: Norfolk rotation; A: unfertilised control; B: $60 \mathrm{t} \mathrm{ha}^{-1} \mathrm{FYM}+\mathrm{NPK}$; C. $5 \mathrm{t} \mathrm{ha}^{-1}$ straw or $7 \mathrm{t} \mathrm{ha-1}$ maize stalks + NPK; D. NPK equivalent to crop uptake, E. NPK for a yield of $15 \mathrm{t} \mathrm{ha}^{-1}$ maize or 10.5 $t h^{-1}$ wheat. Within each crop sequence and fertiliser treatment, data designated by the same letter were not significantly different at the $\mathrm{P}<0.05$ level according to Duncan's multiple range test.

Without mineral fertilisation, the yield-increasing effect of the crop rotation was significantly greater $\left(\mathrm{t} \mathrm{ha} \mathrm{h}^{-1}\right)$ : for maize, MW: 0.715, MA: 1.254, MWA: 1.401, NF: 1.357; for wheat, WM: 0.375, WA: 0.446, WAM: 0.923, NF: 1.666. FYM application or the ploughing in of plant residues (maize stalks, wheat straw) supplemented with NPK were both efficient ways of fertilising maize and wheat. FYM also improves yield stability.

Significantly higher yields were obtained at high NPK mineral fertiliser rates, especially if the proportion of wheat or maize in the sequence was $\geq 50 \%$. It was found that the yield-increasing effect of wheat rotations was not modified by fertilisation. In the case of maize, however, fertilisation reduced the rotation effect by almost 50\% (Berzsenyi et al., 2000).

Maize and soybean yields, under conventional management at the KBS (Kellogg Biological Station) LTER (Long Term Ecological Research) site are similar to the average yields for the United States, wheat yields are higher. The enhanced water storage capacity may explain that yield in the no-till system was $9-21 \%$ higher than were in the conventional 
system. In the reduced-input system, maize and soybean yields slightly exceed those of the conventionally managed system, and wheat yields lag only slightly. The nitrogen deficit especially apparent in the biologically based system, which lacks fertilizer nitrogen inputs. Wheat yields are approximately $60 \%$ of the yields under conventional management. This is in contrast to soybean yields, for which the biologically based system is equivalent to the conventional system (Hamilton et al., 2015).

Figure 9. Effect of crop rotation and fertilisation on the grain yield of wheat compared with a monoculture (1961-2000)
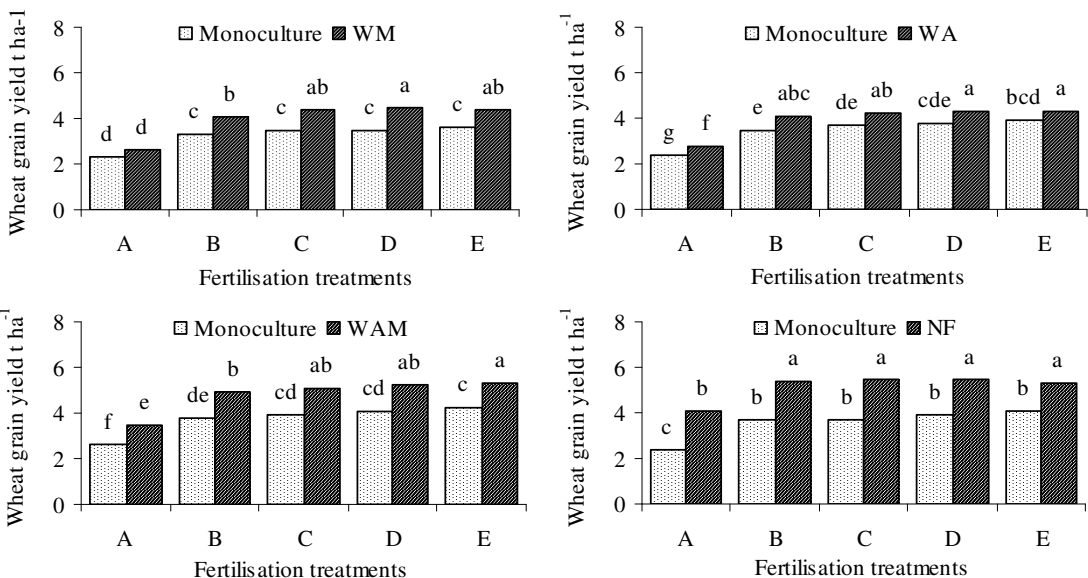

Note: WM: wheat-maize; WA: wheat-alfalfa; WAM: wheat-alfalfa-maize; NF: Norfolk rotation. For further legend, see Figure 1.

\section{Our perspective}

As discussed above, it is obvious that more agricultural production is needed to support increased populations and changing diets while reducing fossil fuel dependence. By properly responding to spatial and temporal variability in soils, crops, and pests, precision agriculture technologies help increase the productivity and efficiency of crop production. The best way to meet the production needs of the future is to use precision agriculture in combination with the best genetics, cultural practices, equipment, and agronomic management, to achieve maximum production. Existing and to-be-developed precision agriculture technologies must be effectively and efficiently integrated into crop production systems to contribute to increased production and sustainability.

We see external inputs and sophisticated technology as essential in agriculture. Without them, productivity will spiral downward leading to 
poverty and starvation for many of the present world population and degradation of soil quality. To be sufficient, agricultural systems must further intensify, which means increasing dependence on external sources of nutrients (Connor et al., 2011).

In the coming decades, human population and income growth will drive agriculture to ever-higher intensities. Now it is time to guide this intensification in a way that enhances the delivery of ecosystem services.

Delaying action will result in an environment further degraded and an agriculture that is more vulnerable to climate extremes and pest outbreaks, and increasingly dependent on external energy and synthetic chemical inputs (Hamilton et al., 2015).

\section{References}

Berzsenyi, Z. (2010): Significance of the 50-year-old long-term experiments in Martonvásár in improving crop production. Acta Agronomica Hungarica. 58 (Suppl.): 23-34.

Berzsenyi, Z.-Györffy, B.-Dang, Q. L. (2000): Effect of crop rotation and fertilisation on maize and wheat yields and yield stability in a long-term experiment. European Journal of Agronomy. 13: 225-244.

Berzsenyi, Z.-Dang, Q. L. (2007): Study of the effect of plant density on the growth of maize (Zea mays L.) hybrids using the Richards function. Acta Agronomica Hungarica. 55. 4: 417-436.

Berzsenyi, Z.-Dang, Q. L. (2008): Effect of various crop production factors on the yield and yield stability of maize in a long term experiment. Cereal Res. Commun. 36. 1: 167-176.

Berzsenyi, Z.-Tokatlidis, I. S. (2012): Density dependence rather than maturity determines hybrid selection in dryland maize production. Agron. J. 104. 2: 331-336.

Connor, R. S.-Loomis, D. J.-Cassman, K. G. (2011): Crop ecology. University Press. Cambridge.

Cooke, G. W. (1982): Fertilizing for maximum yield. Collins. London.

Evans, L. T. (1993): Crop evolution, adaptation and yield. University Press. Cambridge.

Fisher, R. A.-Edmeades, G. O. (2010): Breeding and cereal yield progress. Crop Sci. 50: 433-458.

Gliessman, S. R. (2015): Agroecology. CRC Press. Boca Raton. Fl. USA.

Hamilton, S. K.-Doll, J. E.-Robertson, G. P. (2015): The ecology of agricultural landscapes. Oxford University Press. UK.

Hunt, R. (1982): Plant growth curves: The functional approach to plant growth analysis. Edward Arnold. London. 